\title{
Base Pair Opening Dynamics in Methylated GATC Sites Catalyzed by Ammonia
}

\author{
Jongchul Bang, Sung-Hun Bae, Chin-Ju Park, Joon-Hwa Lee, ${ }^{+* *}$ and Byong-Seok Choi \\ Department of Chemistry and National Creative Research Initiative Center, KAIST, Dacjeon 305-701. Korea \\ ${ }^{\dagger}$ E-mail: byongseok.choiakaistac $\mathrm{kr}$ \\ ${ }^{\dagger}$ Department of Chemistry, RINS, and Environmental Biotechnologv National Core Research Center, \\ Gyeongsang National Lniversity, Jinju, Gyeongnam 660-701, Korea ${ }^{*}$ E-mail: joonhwaragnuac. $k r$ \\ Recerved October 1, 2008. Accepted November 21, 2008
}

Key Words: GATC site, NMR, Base pair opening, Hydrogen exchange, N6-metlylated adenine

DNA methylation regulates various cellular process in most living organism.' Escherichia coli (E.coli) DN $\Lambda$ adcnine (dam) methyltransferase methylates the N6 positions of adenine within the 5'-GATC-3' sequence (Fig. 1). ${ }^{2}$ The dam-melhylation status of $\mathrm{G} A \mathrm{TC}$ sites plays a key role for control of cellular DNA process. . The E coll SeqA protein specilically binds to newly synthesized hemimethylated GA'C site at oriC region during replication and then prevents second replication process. "During DNA mismatch repair, the MutH protein selectively cleaves the unmethylated strand which is newly synthesized during replication, within two strands of hemimethylated GATC site. "The control of DNA process at $\mathrm{GA}^{\prime} \mathrm{J} C \mathrm{C}$ sites might be caused by unique structural or dynamic properties of dum-methylation on DNA. The structural andor dynamic studies of the GATC site with various methylation modifications are required in order to elucidate the mechanism of specific recognition SeqA to hemimethylated GATC in a sea of fully methylated one. Recently, the kinetics and thermodynamies of base-pair openings of the unmethylated

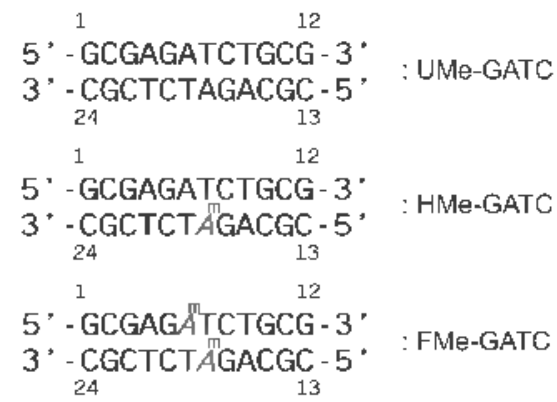

$(B)$

$$
\text { trans-N6-methylated Adenine }
$$

Figure 1. (A) Sequence and numbering of the dodecamer D.VA duplexes that contain (from top to bottom) unmethylated. hemimethylated. and fully methylated GATC sites (referred to as the UMe-(ANC: IIMe-CAIC and IAMe-(BNC duplexes. respectively). $1^{\mathrm{m} \prime}$ indicates an N6-methylated adenine. (13) The Watson-Crick base pajing between a trans-V6-methylated admine residec and its complementary thymine residuc.
(UMe), hemimethylated (HMe), and fully methylated (FMe) G $\Lambda$ TC-containing DNA duplexes using tris(hydroxymethyl) aminomethane (TRIS) were reported. ${ }^{5}$ This study suggested that the faster base-pair opening of the hemimethylated GATC duplex, relative to the fully methylated one, allows the hemimethylated GATC duplex to be recognized easily by the SeqA protein in the background of abundant fully methylated sites. This study also implicated that the lower energy level of the partially opened state of the hemimethylated GATC site, relative to that of the fully methylated one, might be a key factor that contributes to specific complex formation between $\mathrm{Sec} A$ and hemimethylated $\mathrm{G} \wedge \mathrm{TC}$ sites.

NMR hydrogen exchange experiment has been used to probe the thermodynamics and kinetics for base pair opening in a variety of nucleic acids." Ammonia is the most commonly used base catalyst in this study because of its high catalytic efficiency. ${ }^{6.7}$ At high temperature, however, TRIS was used in order to minimize the severe line-broadening caused by strong base catalyst such as ammonia. ${ }^{5.7}$ The catalytic efficiency of base catalyst is affected by its size and charge property. ${ }^{8}$ Iere, we performed ammonia-catalyzing imino proton exchange studies of the three GATC-containing DNA duplexes (Fig. 1) and compared with the result of TRIS-catalyzing exchange study previously reported. ${ }^{5}$ to elucidate the size effect of base catalyst.

All DNA oligonucleotides were purchased from Genolech Inc. (Daejeon, Korea). The oligonucleotides were desalted using a Sephadex G-25 gel filtration column. DNA duplex san-ples were prepared by combining molar equivalent of the two strands in $90 \% \mathrm{H}_{2} \mathrm{O} / 10 \% \mathrm{D}_{2} \mathrm{O}$ NMR buffer containing $10 \mathrm{mM}$ sodium phosphate (pll 6.8) and $100 \mathrm{mM} \mathrm{NaCl}$. For ammonia-catalyzed exchange experiments, the $\mathrm{pH}$ of buffer was change 10 8.0. The ammonia concentration was increased from 0 to $100 \mathrm{mM}$ by addition of a $2 \mathrm{M}$ ammonia stock solution. NMR experiments were performed on a Varian Inova $600 \mathrm{MHz}$. spectrophotometer. All NMR data were processed and analyzed with program VNMRJ and FELIX2004 (Accelrys) as described." Semi-selective inversion recovery I-D NMR experiments were used to determine the determine the apparent longitudinal relaxation rate constants, $R_{\alpha q}\left(=1 / T_{l a}\right)$, of the imino protons.

The formalism of imino proton exchange has been extensively described. ${ }^{5-\bar{T} .16}$ The apparent relaxation rate constant for imino protons $\left(R_{/ r}\right)$ can be represented by: 
(A)

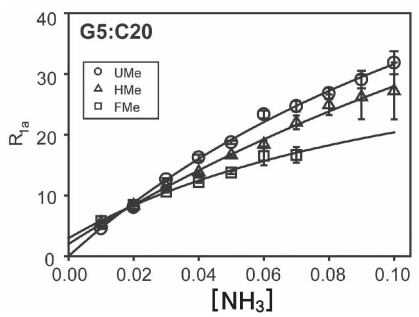

(B)

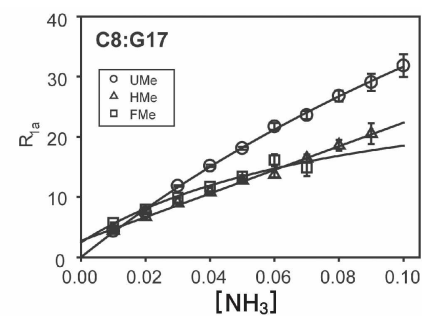

Figure 2. Ammoniadcalalyed exchange experiments carried out with the GATC duplexes. Apparent spin lattice $R_{f}$ relaxation rate constants $\left(R_{t,}\right)$ for the $(A) G 5$ and $(\mathrm{B}) \mathrm{G} 17$ imino protons as a function of the ammonia concentrations are shown. The solid lines are the hest fits to (1). and the error bars represent the fitting crrors during determination of $R_{u}$ using data obtained from inversion recovery experiments.

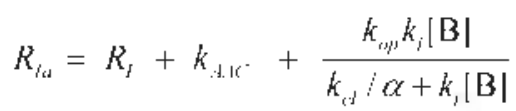

where $R_{I}$ is the relaxation rate constant, $k_{1 r}<$ is the contribution of the intrinsic base, $k_{t, t}$ and $k_{c^{\prime}}$ are the base pair opening and closing rate constants, respectively, $\alpha$ is the accessibility factor which depends on the base catalyst, $k_{j}$ is the proton transfer rate constant by base catalyst, and [B] is the concentration of base catalyst. ${ }^{5.7}$ The apparent equilibrium constant $\left(\alpha K_{r j}\right)$ for the base pair opening can be calculated by $a k_{r \gamma} ; k_{2} /$.

The effects of $\left[\mathrm{NH}_{3}\right]$ on $R_{l s}$ of the imino protons were measured by inversion recovery experiments and results for G5 and $\mathrm{GI} 7$ imino protons are shown in Fig. 2. From these data, the base- pair life times $\left(\tau_{i j}=1 / k_{o p}\right)$ and $\alpha K_{o p p}$ for central four base pairs of three $\mathrm{G} A \mathrm{TC}$-containing $\mathrm{DN} \Lambda$ duplexes were determined by curve fitting using Eq. 1 and listed in Table $\mathrm{I}$. These values were compared with the cortesponding values which had been determined by I'RIS-catalyzing imino proton exchange ex- periments. ${ }^{5}$ The apparent equilibrium constants for the base pait opening of the $\mathrm{G} 5 \times \mathrm{C} 20$ and $\mathrm{C} 8 \mathrm{Gl} 7 \mathrm{de}$ termined using ammonia $\left(\alpha_{,} K_{i p}^{\prime}\right)$ are very similar with the corresponding values $\left(\alpha_{1} K_{\text {ryp }}\right)$ determined using TRIS (Table I). The relative ratio $\left(\alpha_{\gamma} / \alpha_{\gamma}\right)$ of these two corresponding values are in the range from 0.8 to 1,2 , indicating that two base catalysts, ammonia and TRIS, have the same accessibility factors. The ammonia led to rapid exchange for most of the imino protons at $35^{\circ} \mathrm{C}$, because the ammonia ( $\mathrm{pKa} \sim 9.3$ ) is much stronger base catalyst than TRIS (pKa $\sim 7.9$ at $35^{\circ} \mathrm{C}$ ). ${ }^{7}$ ] his phenomcnon is responsible for severe line-broadening under high concentration of ammonia. Thus, in this study, the base-pair life times were determined with very large standard deviations which meant that the values were relatively inaccurate compared to those determined from TRIS-catalyzing experinent.

Surprisingly, the $\alpha K_{\text {ep }}$ of two $\Lambda \cdot T$ base pairs determined by ammonia are $2-3$-fold smaller than those derived from TRIS-catalyzing experiment. This result might be caused by the fast exchange of the A.T base pairs which are relatively less stable than neighboring $G \cdot C$ base pairs. However, this experiment clearly showed that these two $\mathrm{A} \cdot \mathrm{T}$ base pairs in the FMe-GATC duplex are much more stable than the corresponding base pairs in the UMe- and IIMe-G $\triangle \mathrm{TC}$ duplexes.
Table 1. Parameters for ammonia-catalyzing base pair opening of the (ANTC-containing I)N A duplexes at $35^{\circ} \mathrm{C}$

\begin{tabular}{|c|c|c|c|c|c|c|}
\hline \multirow{2}{*}{$\begin{array}{l}\text { Bast } \\
\text { Pair }\end{array}$} & \multirow[b]{2}{*}{ Duplex } & \multicolumn{2}{|c|}{$\mathrm{NH}_{3}$ catalyzits } & \multicolumn{2}{|c|}{ TRIS catalyzing"' } & \multirow[b]{2}{*}{$a_{i} \cdot a_{i}^{\prime}$} \\
\hline & & $\begin{array}{l}a_{n} K_{\text {off }}^{\prime} \\
\left(\times 10^{11}\right)\end{array}$ & $\begin{array}{c}\tau_{11} \\
(\mathrm{~m} . \mathrm{s})\end{array}$ & $\begin{array}{l}\alpha_{i} K_{1, j}^{\prime} \\
\left(\times 10^{\prime \prime}\right)\end{array}$ & $\begin{array}{c}\text { tis } \\
\text { (Ins) }\end{array}$ & \\
\hline \multirow{3}{*}{$\mathrm{G} 5 \mathrm{C} 20$} & UMe & $0.91+0.10$ & $11+3$ & $0.73+0.01$ & 1012 & 1.2 \\
\hline & HMc & $0.64 \pm 0.98$ & $9 \pm 4$ & $0.76 \pm 0.02$ & $24 \pm 4$ & 0.8 \\
\hline & $\mathrm{FMc}$ & $0.59 \pm 0.16$ & $26 \pm 16$ & $0.59 \pm 0.02$ & $64 \pm 7$ & 10 \\
\hline \multirow{3}{*}{$\mathrm{A} 6 \cdot \mathrm{T} 19$} & UME' & $12.3 \pm 3.5$ & $0 \pm 1$ & $41.9 \pm 0.7$ & $1 \pm 1$ & 0.3 \\
\hline & 11Me & $7.7 \times 6.5$ & 819 & $17.5+0.3$ & 211 & 0.4 \\
\hline & $\mathrm{FML}^{\mathrm{c}}$ & $4.9 \pm 2.3$ & $10 \pm 6$ & $8.3 \pm 0.1$ & $3 \pm 1$ & 0.6 \\
\hline \multirow{3}{*}{$37 \cdot A 18$} & पIMe" & $12.3 \pm .3 .5$ & $0 \pm 1$ & $41.9 \pm 0.7$ & $\mathrm{I} \pm \mathrm{l}$ & 0.3 \\
\hline & 1]Me & $8.0 \pm 27.8$ & $8 \pm 9$ & $18.7 \pm 0.3$ & $2 \pm 1$ & 0.4 \\
\hline & l: $\mathrm{Me}^{\prime}$ & 4.912 .3 & 1016 & $8.3+0.1$ & 311 & 0.6 \\
\hline \multirow{3}{*}{$\mathrm{C} 8 \mathrm{Gi7}$} & lIMe & $0.80 \pm 0.05$ & $8 \pm 2$ & $0.79 \pm 0.01$ & $8 \pm 1$ & 1.0 \\
\hline & llike & $0.37 \pm 0.04$ & $0 \pm 6$ & $0.49 \pm 0.01$ & $9 \pm 6$ & 0.8 \\
\hline & line & $0.65 \pm 0.35$ & $33 \pm 32$ & $0.64 \pm 0.01$ & $65 \pm 5$ & 10 \\
\hline
\end{tabular}

"data of reterence (5): "relative ratio of $\alpha K_{c p}$, and $\alpha, K_{i p,}$; "T19 and T7 resonances are overlapped each other

This implies that the ammonia-catalyzing exchange experiment performed at high temperature cannot give us the exact parameter for base pair opening but provides the relatively exact thermal stabilities of the interesting system.

In conclusion, we determined the parameters for base pair opening of three GAlC-containing DNA duplexes using ammonia as base catalyst and the results were compared with the corresponding values derived from TRIS-catalyzing exchange experiment previously reported. Ammonia has the same accessibility factor with TRIS and both base catalysts give the similar $\alpha K_{(y)}$ for very stable base pairs. In contrast, it is difficult to detemine the exact parameters for base pair opening of less stable base pairs using ammonia but the relative base pair stability can be estimated exactly.

Acknowledgments. This work supported by a grant from the National Creative Research Initialive Program (1o B.-S.C.) and a grant to EB-NCRC (R15-2003-012-01001-0) and the KOSFF Grant (R01-2007-000-10691-0) and KRF Grant (KRF-2008-33l-C00178) (to J.-H.L.) funded by the Korean Government (MEST). 1.B. was supported by the BK21 project from Korean Government (MEST).

\section{References}

I. Jeltsch. A. Chembiochem 2002. 3. 274-293.

2. Geier. (i. F:.: Modrich, P, J. Biol. (hem 1979, 25t, 1408-1413.

3. Lu. M.: Campbell. J. L.: Boye. E.: Kleckner. N. Ce/l 1994. 77. 413-426.

4. Modrich. P. Anmut Rev Genet 1991, 25. 229-253

5. Bang. J.: Bac. S. H.: Park. C.-J.: Lce. J.-H.: Choi. B.-S. J. Am. Chem. Soc 2008. 130. 17688-17696.

6. Gueron. M.: I eroy I. I. Wethods En-1mof 1995, 26/, 383-413.

7. Lec. J.-H.: Pardi. A. Nucteic Acids Res. 2007. 35. 2965-2974.

8. Snoussi. K.: Leroy. I. 1. Biochemistry 2001. 40. 8898-8904.

9. Lee. J.-H.: Park. C.-J.: Choi. B.-S. Bull. Korem Chem. Soc. 2006. 27. 1731-1732.

10. Leroy. J. 1..: Bolo. N.: Figueroa. N.: I'lateau. P.: Gueron. M. .J. Bionol. Siruct. Din. 1985. 2. 915-939. 